Chapter 8

\title{
Highlights on Anopheles nili and Anopheles moucheti, Malaria Vectors in Africa
}

\author{
Christophe Antonio-Nkondjio and Frédéric Simard \\ Additional information is available at the end of the chapter \\ http://dx.doi.org/10.5772/55153
}

\section{Introduction}

Anopheles nili Theobald 1904 and An. moucheti Evans 1925 are major human malaria vectors in forested and humid savannah areas of West and Central Africa [1]. Yet, they remain critically understudied and basic knowledge on their biology, ecology and genetics is crucially lacking [2]. To date, most studies of African malaria vectors have focused on An. gambiae, An. arabiensis, and An. funestus, in part, because molecular and cytogenetic tools for characterizing population structure, ecological adaptation, and taxonomic status of other species have been lacking until recently. Further, no laboratory colony is available for experimental work involving these neglected species. This gap in knowledge needs to be addressed for successful implementation of global strategies for malaria elimination and eradication in the Afrotropical region [3].

Recent studies of the ecological niche profile of major African malaria vectors demonstrated that the habitats of An. gambiae, An. arabiensis, and An. funestus have more overlap with each other than with the habitat of $A n$. nili and An. moucheti [4-7]. This results in an unual geographic distribution of An. nili and An. moucheti (Figure 1), revealing their crucial role in malaria transmission in forested and degraded forest areas of equatorial Africa [8-13]. Unique aspects of ecological adaptation and behaviour can, in part, explain the increased vectorial capacity of the species in these environments and might protect them from conventional vector control tools targeting highly endophilic and endophagic mosquito species [3, 14]. Moreover, the recent findings of circulation of Plasmodium falciparum along with other Plasmodium species in great apes and monkeys [15-17] raise concerns about pathogen transfer between humans and primates and further highlight the need to improve our knowledge of forest malaria vectors.

In this chapter, we review knowledge gained so far on mosquitoes from An. moucheti and closely related species, as well as the An. nili complex. We highlight specific bionomical, 
ecological and genetic attributes that distinguish these species from the most well-known major African malaria vectors, providing opportunities for further research on neglected aspects of vector biology and control.

\section{Anopheles moucheti and closely related species}

Anopheles moucheti belongs to the series Myzomyia and closely resembles Anopheles marshallii Theobald of the Marshallii complex. This close morphological similarity resulted in $A n$. moucheti being initially considered a variety of An. marshallii before it was raised to the rank of full species on the basis of morphological and bionomic differences [18]. However the taxonomic status of $A n$. moucheti has been subject to several interpretations during the past decades. Based on morphological similarities between An. bervoetsi and An. moucheti nigeriensis, Anopheles moucheti was later considered by Brunhes et al. [19] as a group consisting of three morphological forms, namely An. moucheti moucheti (referred to as the type form), An. moucheti bervoetsi and An. moucheti nigeriensis distinguishable by slight morphological characters present at the adult and/or at the larval stages $[2,19,20]$. In their classification, Brunhes et al. [19] referred to An. bervoetsi as a subspecies of $A n$. moucheti while they suggested to put in synonymy An. m. nigeriensis and the type form. Genetic analysis conducted subsequently provided evidences against any taxonomic value for this morphological classification [21-23]. Recent classification by Harbach [24] recognizes An. moucheti and An. bervoetsi as formal species while $A n$. m. nigeriensis is considered as a morphological variant within An. moucheti.

Anopheles moucheti is widely distributed across West and Central Africa (Figure 2) whereas the two other taxa have only been reported so far from their type locality in Nigeria near Lagos $\left(06^{\circ} 27^{\prime} \mathrm{N}\right.$; $\left.03^{\circ} 24^{\prime} \mathrm{E}\right)$ for An. moucheti nigeriensis and in Tsakalakuku $\left(06^{\circ} 34^{\prime} \mathrm{S} ; 1^{\circ} 35^{\prime} \mathrm{E}\right)$ in the Democratic Republic of Congo (DRC) for An. bervoetsi [18].

Anopheles mouchet $i$ is among the most important human malaria vectors in the equatorial forest region of Africa, particularly in villages situated along slow moving rivers or streams where its larvae develop in and around floating vegetation and debris (Figure 3) [4, 5]. Larval collections to assess ecological factors influencing An. moucheti distribution across river networks in south Cameroun showed that An. moucheti larvae are frequently associated with lentic rivers, low temperatures and the abundance of aquatic vegetation at the edge of the river (Figure 4) [5]. Increased urbanization and deforestation as well as lower-scale landscape modification such as river banks cleaning for gardening and/or recreational purposes were shown to be highly detrimental to the species, fostering changes in the malaria vector system composition with a higher prevalence of An. gambiae, taking the lead over An. moucheti [9]. Insecticide susceptibility tests conducted on several populations from South Cameroon in 2007 indicated that An. moucheti is fully susceptible to DDT, permethrin and deltamethrin (Etang et al., unpublished data).

In rural villages situated in deep forest areas, An. moucheti usually is the major vector of Plasmodium, and quite often the only one maintaining a high level of malaria endemicity in humans. Natural infection rates in the range 1-3\% are commonly reported in wild females, 

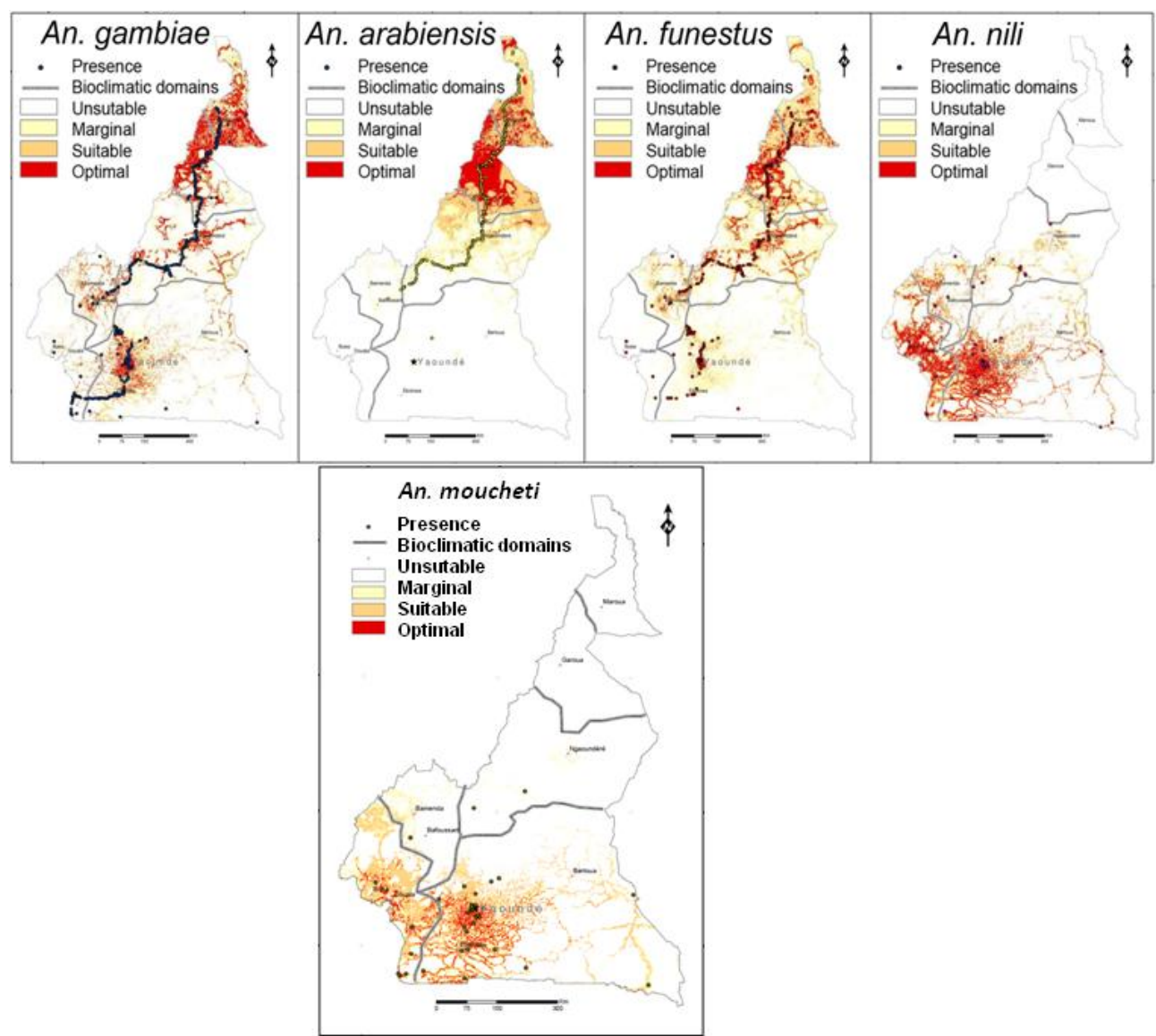

Figure 1. Habitat suitability maps for the five major malaria vectors in Cameroon. A/ Anopheles gambiae, An. arabiensis, An. funestus, , An. nili, An. moucheti. Different colors identify four classes of habitat quality including optimal (red), suitable (orange), marginal (yellow) and unsuitable habitat (white). Figure drawn from Ayala et al., 2009 [4].

sustaining annual entomological inoculation rates (EIR) reaching up to 300 infective bites/ human/year [27, 28]. As such, the species has been incriminated in malaria transmission in a number of countries in Central Africa, including Nigeria [29], Cameroon[28, 30], Gabon [31, 32], Equatorial Guinea [10, 11], Congo [18], the DRC [18] and Uganda [18]. In these settings, An. moucheti frequently bites indoors and high densities of blood-fed females can be collected resting indoors, over $95 \%$ of which had taken their blood meal on humans demonstrating strong anthropophily. However, high mosquito densities might also be collected far from any human settlements, indicating a probable zoophilic behaviour in some forest populations [33,34].

Anopheles bervoetsi has only been reported so far from its type locality and surrounding villages in the DRC. Larvae are found in small rivers sheltered by forest galleries that wind through the valleys in a hilly landscape. Adults are highly anthropophilic and preferentially bite 


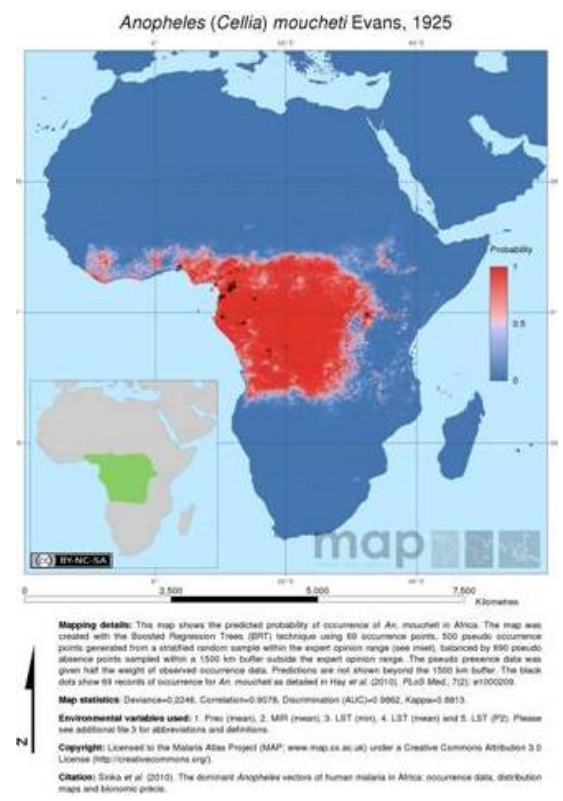

Figure 2. Map of the predicted probability of occurrence of Anopheles moucheti in Africa (redrawn from [25]). Black dots represent 69 records of occurrence for An. moucheti as described in Hay et al. [26].

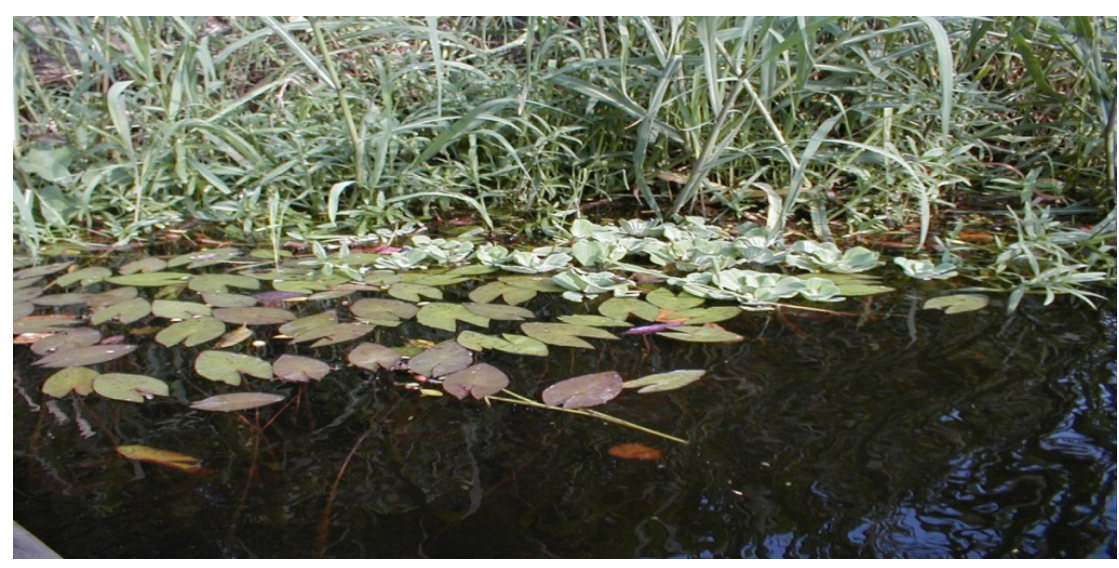

Figure 3. A typical breeding site for Anopheles moucheti larvae along river Nyong in southern Cameroon.

outdoors. However, it can be collected biting and resting indoors when abundance is high at the end of the rainy season (Antonio-Nkondjio et al. unpublished data). Biting occurs at night with a peak of activity usually recorded in the second part of the night. A recent study reported three specimens found infected by Plasmodium falciparum out of 237 tested by ELISA, confirming its role in malaria parasites transmission [35]. 


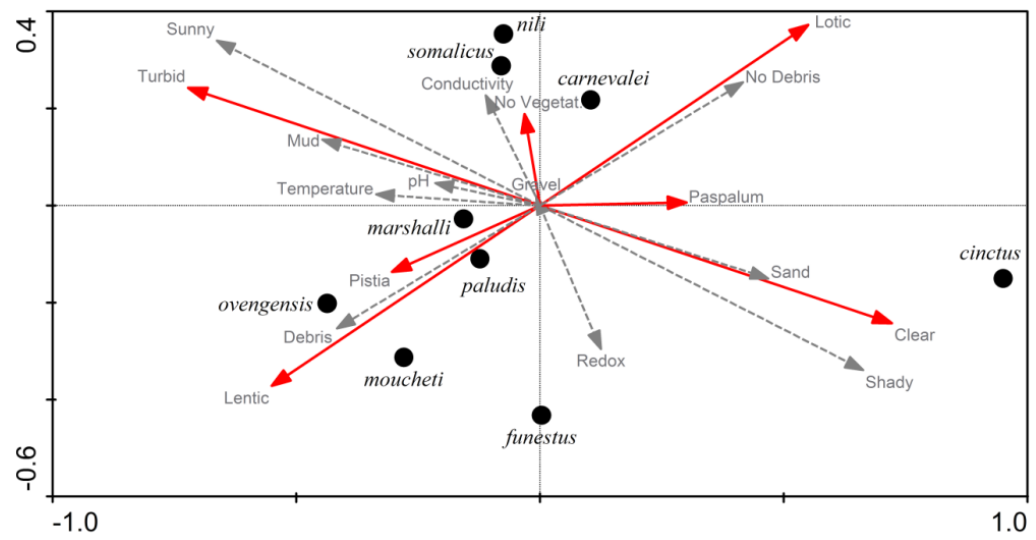

Figure 4. Canonical Correspondence Analysis (CCA) diagram showing the ordination of anopheline species along the first two axes and their correlation with environmental variables. The first axis is horizontal, second vertical. Direction and length of arrows shows the degree of correlation between mosquito larvae and the variables. Figure drawn from Antonio-Nkondjio et al.[5].

Anopheles $m$. nigeriensis is considered as a synonym to An. moucheti, due to the absence of reliable morphological differences at the adult and larval stages between the two morphs [19, 24]. Nothing is known of the species bionomics. The only report of its implication in malaria parasites transmission is from Baber and Olinger in 1931 ([18], loc. cit.) who reported 1 in 87 mosquitoes infected with sporozoites. Collections conducted in its type locality in 2005 reported few specimens ( $<10$, Antonio-Nkondjio and Simard, unpublished data), probably reflecting habitat deterioration due to the expansion of the urban domain around Lagos.

From morphological analysis (Figure 5), it appears that the type form could display high morphological variation with variants similar to An. m. nigeriensis and An. bervoetsi. However, genetic investigations and the follow-up of morphological diversity in the progeny of field collected gravid females demonstrated that a single taxon was represented, at least in Cameroon [21]. Population genetic investigations using a set of ten microsatellite markers [36] further strengthened this view, revealing genetic homogeneity between natural populations of An. moucheti in South Cameroon and throughout Central Africa, including Uganda and the DRC $[36,37]$. Studies comparing sequence variations in nuclear (rDNA Internal Transcribed Spacer 1, ITS2 and the D3 domain of the 28 S ribosomal subunit) and mitochondrial (cytochrome b) DNA regions were also concordant, depicting a low level of genetic diversity and differentiation between specimens from Cameroon, Uganda and the DRC and confirming the high genetic homogeneity of An. moucheti populations throughout Central Africa [23]. However, when mosquito samples collected from the type localities of An. bervoetsi and An. $m$. nigeriensis were included in the analyses, sequence differences were detected between the three taxa, similar in degree to the differences found previously between sibling species within other anopheline groups or complexes [23]. An allele specific PCR assay based on sequence differences in the rDNA ITS1 region was developed to allow rapid identification of each of these three genetic lineages (Figure 6) [23]. Microsatellite analysis further demonstrated 
significant genetic differentiation between An. bervoetsi populations form the DRC and An. moucheti populations from Cameroon, suggesting that they represent two different species [35]. In light of accumulating evidences (morphological, behavioral and genetic differences) this taxa was raised to the rank of full species and named An. bervoetsi [35] [24]. Yet the issue of the taxonomic status of $A n$. m. nigeriensis remains unresolved. It might still be considered as a variant of An. moucheti to be further studied.

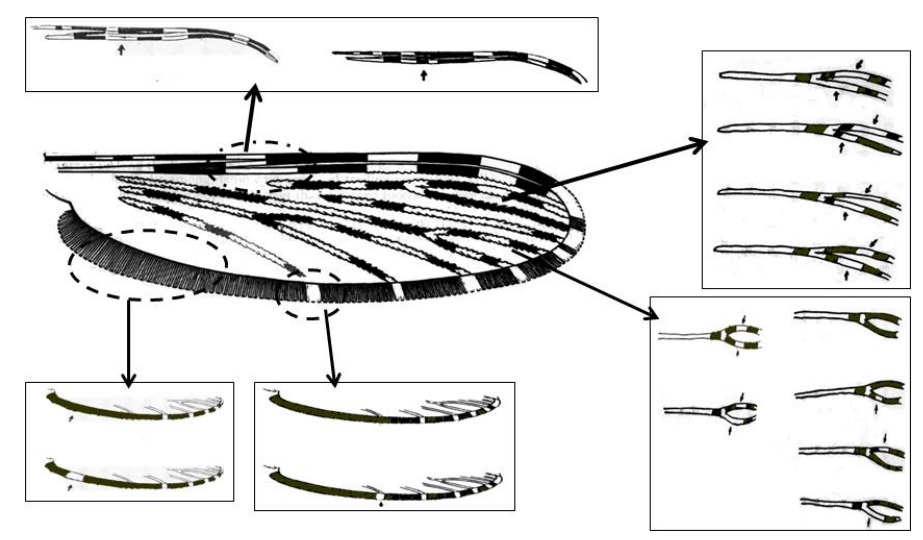

Figure 5. Morphological variations on the wing of An. moucheti.

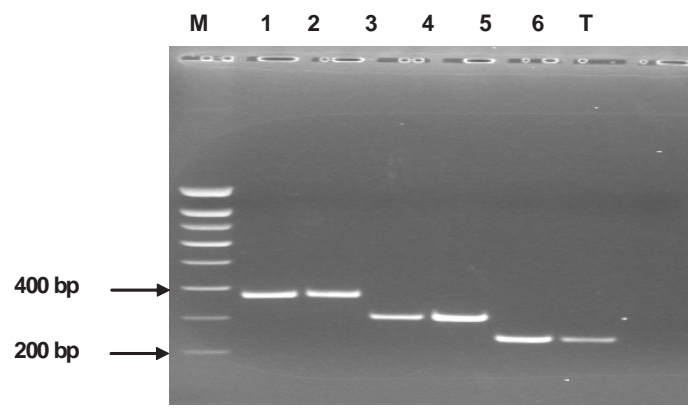

Figure 6. An agarose gel stained with ethidium bromide revealing size differences in the PCR amplification products discriminating An. moucheti and closely related species: An. bervoetsi (lanes 1 and 2), An. moucheti (lanes 3 and 4 ) and An. m. nigeriensis (lanes 5 and 6). Figure from Kengne et al., 2007 [23]

\section{Anopheles nili complex}

Important morphological, ecological and behavioral differences among natural populations of Anopheles nili from sub-Saharan Africa suggested the existence of several taxonomic units 
and resulted in the description of four formal species, namely: Anopheles nili sensu stricto, An. somalicus, An. carnevalei and An. ovengensis [20,21]. Morphologically, these four species are very close from one another, differing only through subtle morphological characters present at the adult and/or at the larval stages (Figure 7) [18, 38, 39]. Apart from An. somalicus, which is zoophilic and was never incriminated in human malaria transmission, the three other members of the complex are highly anthropophilic and are vectors of malaria.

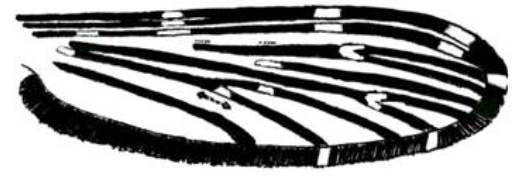

A

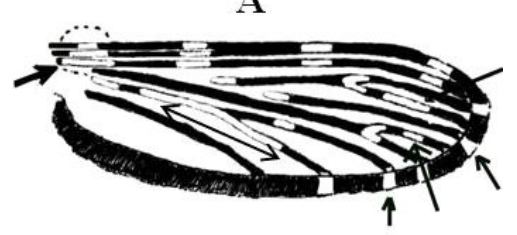

B

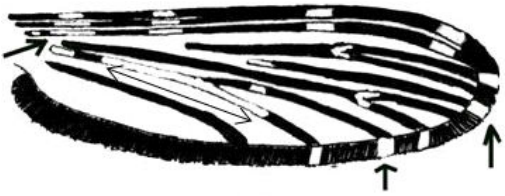

C

Figure 7. Morphological differences between members of the An. nili complex. A: wing of An. nili and An. somalicus, B: wing of An. carnevalei, C: wing of An. ovengensis.

Anopheles nili s.s. is among the most important malaria vectors in sub-Saharan Africa. It has a wide geographic distribution range spreading across most of West, Central and East Africa mainly populating humid savannas and degraded rainforest areas (Figure 8) [1, 4, 20, 40]. Larvae thrive at the sunny edge of fast running streams and rivers, where floating vegetation and debris provide suitable shelters (Figure 9) [32]. Forest populations are usually highly anthropophilic and feed regularly indoors whereas savanna populations are more exophilic and exophagic [12, 28]. Despite feeding preferentially on humans, this mosquito can be, at times highly zoophilic [41]. Anopheles nili is usually responsible for a high nuisance to humans in villages along rivers, and abundance rapidly decreases within a few kilometers from the breeding sites [42]. It is also present at the periphery of urban areas.

The prevalence of Plasmodium infections in wild females typically ranges between 1 and 3\%and transmission rate reaching 200 infective bites/human/year have been reported in the literature for An. nili [12, 13, 28, 43]. Reports on its epidemiological role in East Africa however, are scarce, dating back to the 1970s $[18,44]$. There is no published record available for insecticide 
susceptibility in An. nili populations, although unpublished results from South Cameroon suggest full susceptibility to DDT and pyrethroids (permethrin and deltamethrin) using the diagnostic doses recommended for assessing An. gambiae populations (Etang et al., unpublished data). The analysis of key ecological factors associated with the distribution of An. nili larvae across 24 hydrographic networks in Cameroon showed that An. nili distribution conforms to that of a generalist species which is adapted in exploiting a variety of environmental conditions (Figure 4).

Anopheles carnevalei and An. ovengensis are mainly distributed in deep forest areas where they take over An. nili s.s. in this environment [4, 41]. Anopheles carnevalei has been reported so far only from Côte d'Ivoire, Cameroon and Equatorial Guinea [10, 11, 38]. It is rarely collected resting indoors and bites more frequently outdoors [12]. This mosquito is mostly zoophilic although it regularly feeds on humans in villages situated close to its breeding sites. Interestingly, although biting activity can be detected all night long, man-biting activity peaks early in the evening, between 6-7 PM, when inhabitants traditionally meet at the river for domestic and body care activities [12]. Studies conducted in Cameroon and Equatorial Guinea reported infection rates circa $1 \%$ in Cameroon [12, 28], raising up to $24 \%$ when using PCR-based protocols for parasite detection in specimens from Equatorial Guinea [10].

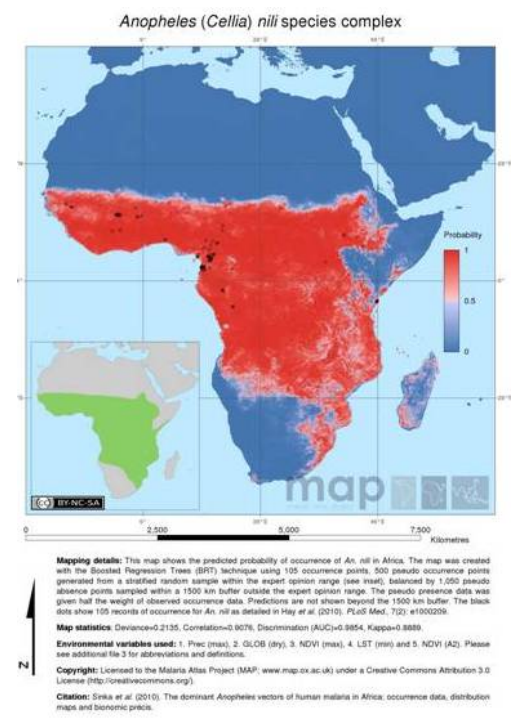

Figure 8. Map of the predicted probability of occurrence of Anopheles nili complex in Africa [25]. Black dots represent 105 records of occurrence for An. nili complex as described in Hay et al. [26].

Anopheles ovengensis, the most recently described species of the An. nili complex, is highly anthropophilic, and bites and rests frequently outdoors [39]. However, studies conducted in Equatorial Guinea reported high densities collected by window exit traps indicating some degree of endophagic and endophilic behavior [11]. Anopheles ovengensis usually displays high 


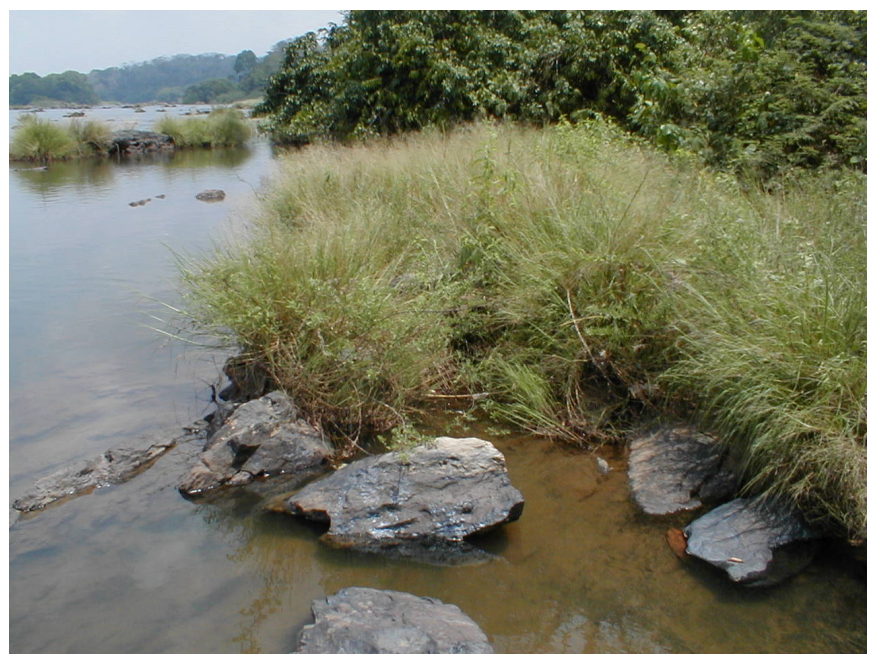

Figure 9. A typical breeding site for An. nili along the river Sanaga in South Cameroon.

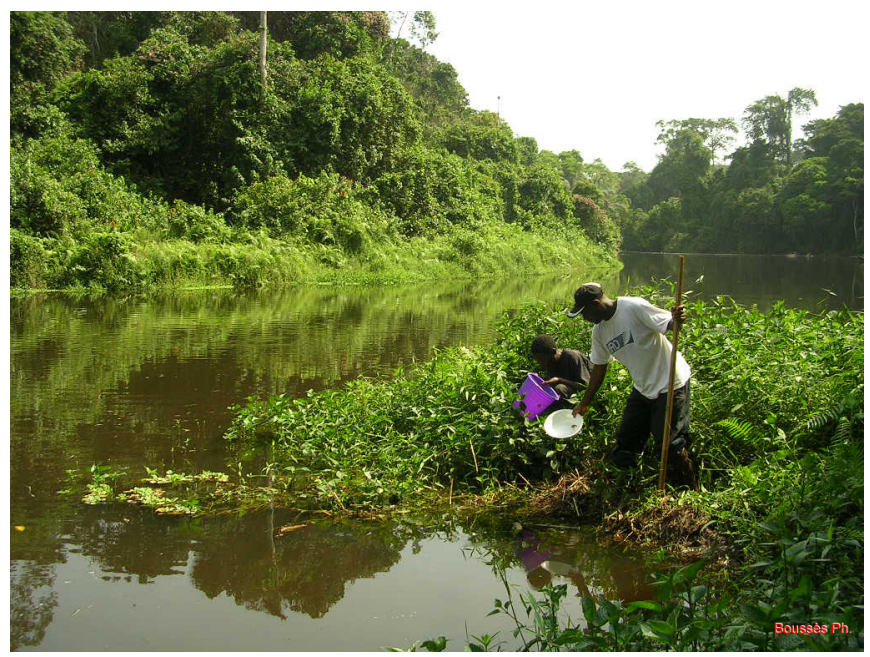

Figure 10. A typical breeding site for An. ovengensis along river Njoh in South Cameroon (Photo: P Bousses, IRD/MIVEGEC).

biting rates for humans, ranging from 50 to 300 bites/man/night along rivers where its larvae develop (Figure 10). Infection rates by P. falciparum ranges between 0.4 to $4.4 \%$ in specimens from Cameroon [39] and in Equatorial Guinea [11]. Larvae are often found in sympatry with those of An. moucheti with whom it shares most of its distribution area. The distribution range of the species probably extends further East, throughout the Congolese forest basin but this has not been investigated yet. 
Anopheles somalicus is strictly zoophilic. At the adult stage, An. somalicus closely resembles An. nili from which it can be morphologically separated at the larval stage only [18]. Adults are rarely recorded in villages although larvae are always found in sympatry with those of $A n$. nili [5]. Nothing is known of its bionomics. According to Gillies and De Meillon [18] its distribution range includes Sierra Leone, Guinea, Burkina Faso, Ivory Coast, Cameroon, Somalia and Tanzania.

Genetic studies conducted on the An. nili complex using various molecular markers confirmed the high genetic heterogeneity among its members [2]. Multilocus enzyme analysis of the genetic variability detected species-specific alleles and large differences in shared allele frequencies among species of the complex collected in South Cameroon [45]. Analysis of sequence polymorphism in the rDNA ITS2 region estimated genetic distances in the range of 0.11-0.25 between the four species [46]. This heterogeneity in ITS2 DNA sequences was further used to develop a PCR-based protocol for molecular identification of the different species within the complex (Figure 11) [46]. These data provided support for the recent taxonomic classification within the An. nili complex [24].

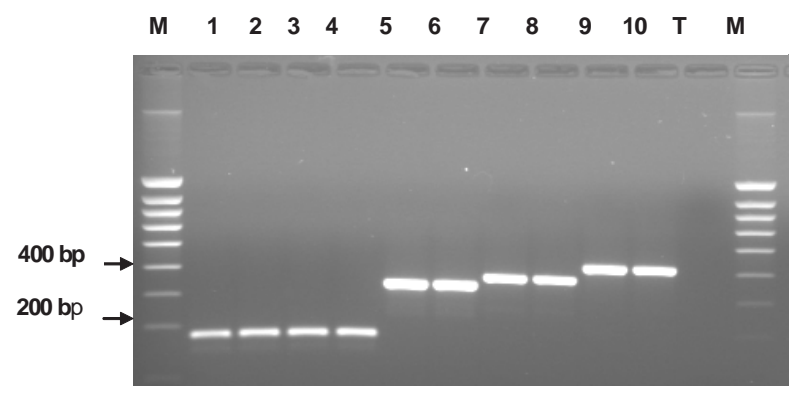

Figure 11. An agarose gel stained with ethidium bromide revealing size differences in the PCR amplification products discriminating between members of the An. nili complex: An. nili (lanes 1 to 4), An. somalicus (lanes 5 and 6), An. ovengensis (lanes 7 and 8) and An. carnevalei (lanes 9 and 10). Figure from Kengne et al., 2003 [46].

Microsatellite loci were developed in 2003 to allow for more in-depth population genetics investigations [47]. A first comprehensive study explored the level of genetic variability and differentiation between nine populations of An. nili distributed in West and central Africa, including samples from Senegal, Ivory Coast, Burkina Faso, Nigeria, Cameroon and the DRC using a set of 11 microsatellite markers and sequence variation in four genes within the nuclear rDNA subunit (ITS2 and D3) and mtDNA (COII and ND4). High genetic homogeneity was revealed among An. nili populations distributed from Senegal to Cameroon, suggesting shallow population substructure throughout the humid savannas of West Africa, in agreement with a weak effect of geographic distance [48]. However, the population sampled in DRC was highly significantly differentiated from the core of West African populations $\left(F_{S T}>0.118\right.$, $\mathrm{P}<0.001$ ), and all individuals segregated into a single genetic cluster separated from all other West African populations in Bayesian cluster analysis (Figure 12). Sequence variation in mtDNA genes matched these results, whereas low polymorphism in rDNA genes prevented 
detection of any population substructure at this geographical scale in savannah populations [48]. Extensive allele sharing between populations and homogeneity across microsatellite loci in the level of genetic differentiation suggested that enhanced genetic drift in the DRC population, rather than selection was responsible for the observed pattern.

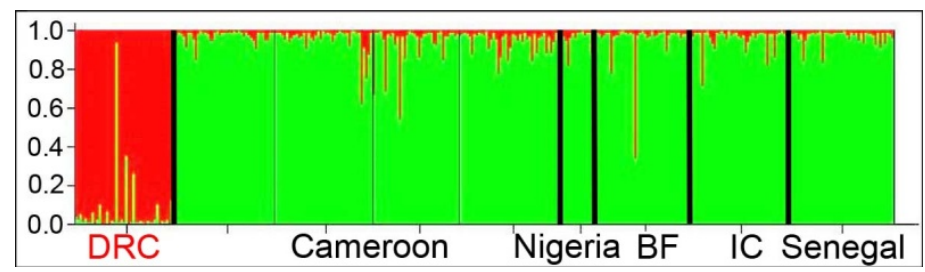

Figure 12. Bayesian genetic cluster analysis of microsatellite allele frequencies in An. nili s.l. populations. Genetic homogeneity within savannah populations of An. nili s.s. from West/Central Africa and high genetic drift in the DRC population.

In Cameroon, the pattern of genetic differentiation was explored among species within the An. nili complex and between populations of An. nili collected in different ecological settings including the deep evergreen forest, deforested areas and savannah areas. The average observed heterozygosity varied from 0.359 for An. ovengensis to 0.661 for An. nili s.s. and mean pairwise $F_{S T}$ over all loci varied from 0.281 (between $A n$. nili and An. carnevalei) to 0.416 (between An. somalicus and An. ovengensis) and were highly significant $(\mathrm{P}<0.0001)$ [45]. The limited number of loci which could readily amplify and the high proportion of loci departing from Hardy-Weinberg equilibrium in samples collected from the deep forest region suggested the presence of new taxonomic units in this area. Up to seven clusters could be identified in An. nili after processing Bayesian cluster analysis (Figure 13). Two of these clusters were specific for An. nili populations collected in the East Cameroon forest area, suggesting that $A n$. nili from East Cameroon may consist of four new taxa. Data obtained from microsatellites analysis were consistent with the high genetic distance measured with rDNA and mtDNA genes [49].

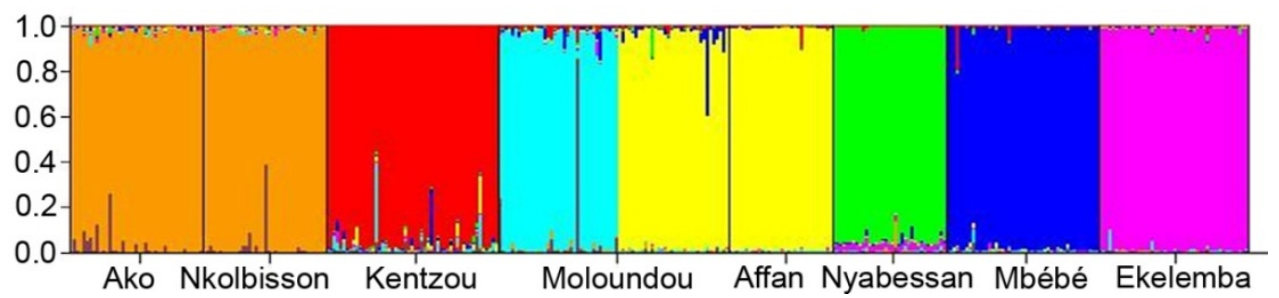

Figure 13. Bayesian genetic cluster analysis of microsatellite allele frequencies in An. nili s.l. populations. Genetic heterogeneity between forest populations of An. nili s.l. in South Cameroon showing genetic clustering of An. carnevalei (yellow), An. ovengensis (green), An. somalicus (dark blue) and the four genetic clusters suggesting further taxonomic subdivision within An. nili s.s. in this area. 
Recently, cytogenetic analysis depicted a physical chromosome map for An. nili upon which nine microsatellite markers could be mapped (Figure 14) [50,51]. Chromosomal arm homology with An. gambiae was assessed by fluorescent in situ hybridization of DNA probes which established that chromosomes X, 2R and 3R are homologous between the two species, while the 2L arm of An. gambiae corresponds to the $3 \mathrm{~L}$ arm of $A n$. nili, and vice versa [50]. Preliminary analysis of chromosomal polymorphism in natural An. nili populations from Burkina Faso and Cameroon demonstrated that two polymorphic inversions, named $2 \mathrm{R} b$ and $2 \mathrm{R} c$, are often present simultaneously on the right arm of chromosome $2[50,51]$.

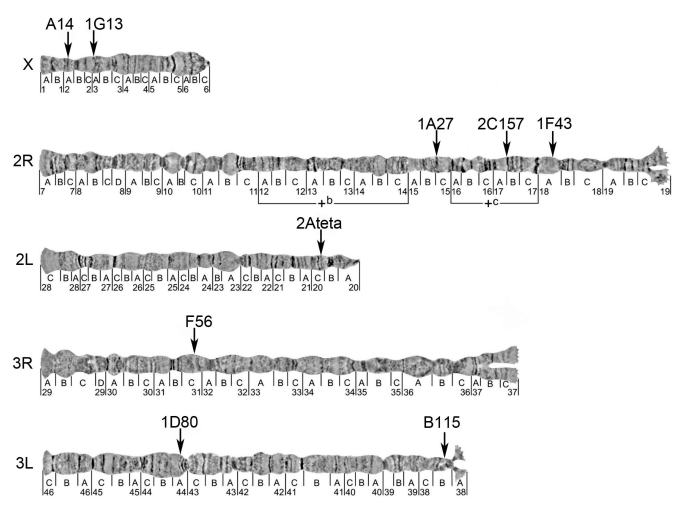

Figure 14. Physical chromosome map of An. nili showing the cytological location of the nine microsatellite markers mapped on polytene chromosomes (arrows). Two chromosomal inversions are indicated by brackets. Figure from Peery et al., 2011 [51].

Frequencies of inverted and standard $2 \mathrm{R} b$ variants were almost equal in the savannah areas of Burkina Faso, albeit with strong deficit in heterozygotes (Fis $=+0.603, \mathrm{P}<0.0001$ ). In forest areas of Cameroon, only the standard arrangement was found. It is postulated that this inversion may be involved in local ecological or behavioral adaptation in An. nili [50]. Inversion $2 \mathrm{R} c$ occurred at high frequency in Burkina Faso (83\%) while its frequency was only $0.6 \%$ in samples from Cameroon, suggesting its involvement in ecogeographic cline from dry to more humid environments. Because An. nili is a forest-savannah transition species, polymorphic inversions could provide genetic plasticity that allowed its expansion into dry savannah and deforested areas of central Africa, where most of the human population is present. High frequencies of these inversions in savannah areas make them useful markers for studying ecological adaptations of this important vector.

\section{Conclusion}

Most of the work on malaria vectors has been conducted in the savannah environment, whereas principal vectors and their roles in malaria transmission in the immense African 
rainforest have barely been explored. Therefore, data are crucially lacking for a large part of Africa where malaria transmission is both intense and permanent throughout the year. Recent results demonstrated high levels of differentiation between populations/species of $A n$. moucheti and the An. nili complex over short geographic distances within the forest block but not in the savannah. These data suggest that, unlike other major vectors, these mosquitoes originated and speciated in the equatorial forest. Because malaria elimination in forested areas is most difficult, detailed understanding of the genetic structure, gene flow, and species diversity of malaria vectors is important. Original information gained on the genetic structure of An. moucheti and An. nili can further be used to investigate genes for a signature of selection to uncover the genetic mechanisms of ecological adaptations, speciation, and susceptibility to Plasmodium, within a comparative framework that will use information available for other major human malaria vectors. Furthermore, because some species/populations within $A n$. moucheti and the An. nili complex are highly exophagic/exophilic and can bite man as well as other vertebrates in remote areas, they are likely candidates for acting as bridge vectors, providing opportunities for wildlife pathogens to cause zoonosis in humans. These findings raise a concern in the light of recent reports confirming the circulation of various Plasmodium species, including strains of P. falciparum, in chimpanzees, gorillas, and guenons in the equatorial forest region [52].

\section{Acknowledgements}

Part of the work reported in this manuscript was supported by grants no. A00942, A20727, A60347 from the UNDP/World Bank/WHO Special programme for Research and Training in Tropical Diseases (TDR) to C.A.N, a Wellcome Trust Intermediate Fellowship in Public Health and Tropical Medecine (WTO86423MA) to CAN, the NIH grant R21 AI079350, the Pal+ programme from the French Ministry of Research and the French Institut de Recherche pour le Développement (IRD/MIVEGEC).

\section{Author details}

Christophe Antonio-Nkondjio ${ }^{1,2^{*}}$ and Frédéric Simard ${ }^{3}$

*Address all correspondence to: antonio_nk@yahoo.fr

1 Laboratoire de Recherche sur le Paludisme, Organisation de Coordination pour la lutte Contre les Endémies en Afrique Centrale (OCEAC), Yaoundé, Cameroon

2 Faculty of Health Sciences University of Bamenda, Bambili, Cameroon

3 Institut de Recherche pour le Développement (IRD), UMR IRD -CNRS 5290-Université de Montpellier 1-Université de Montpellier 2 MIVEGEC (Maladies Infectieuses et Vecteurs : Ecologie, Génétique, Evolution et Contrôle), Montpellier Cedex 5, France 


\section{References}

[1] Mouchet J, Carnevale P, Coosemans M, Julvez J, Manguin S, Richard-Lenoble D, Sircoulon J: Biodiversité du paludisme dans le monde: Paris: John Libbey Eurotext; 2004.

[2] Fontenille D, Simard F: Unravelling complexities in human malaria transmission dynamics in Africa through a comprehensive knowledge of vector populations. Comp Immun Microbiol Infect Dis 2004, 27:357 - 375.

[3] malERA Consultative Group on Vector Control: A research agenda for malaria eradication: vector control. PLoS Med 2011, 25(8):e1000401.

[4] Ayala D, Costantini C, Ose K, Kamdem G, Antonio-Nkondjio C, Agbor J, AwonoAmbene P, Fontenille D, Simard F: Habitat suitability and ecological niche profile of major malaria vectors in Cameroon. Malar J 2009, 8:307.

[5] Antonio-Nkondjio C, Ndo C, Costantini C, Awono-Ambene H, Fontenille D, Simard F: Distribution and larval habitat characterization of Anopheles nili and An. moucheti along river networks in south Cameroon. Acta Trop 2009, 112:270 - 276.

[6] Moffett A, Shackelford N, Sarkar S: Malaria in Africa: vector species' niche models and relative risk maps. PLoS ONE 2007, 2:e824.

[7] Sinka M, Bangs M, Manguin S, Rubio-Palis Y, Chareonviriyaphap T, Coetzee M, Mbogo C, Hemingway J, Patil A, Temperley W et al: A global map of dominant malaria vectors. Parasites $\mathcal{E}$ Vectors 2012, 5(1):69.

[8] Antonio-Nkondjio C, Awono-Ambene H, Toto J, Meunier J, Zebaze-Kemleu S, Nyambam R, Wondji C, Tchuinkam T, Fontenille D: High malaria transmission intensity in sub-urban area of Yaounde: the capital city of Cameroon. J Med Entomol 2002, 39:350 - 355.

[9] Antonio-Nkondjio C, Simard F, Awono-Ambene P, Ngassam P, Toto J, Tchuinkam T, Fontenille D: Malaria vectors and urbanization in the equatorial forest region of south Cameroon. Trans R Soc Trop Med Hyg 2005, 99:347 - 354.

[10] Cano J, Descalzo M, Moreno M, Chen Z, Nzambo S, Bobuakasi L, Buatiche J, Ondo M, Micha F, Benito A: Spatial variability in the density, distribution and vectorial capacity of anopheline species in a high transmission village (Equatorial Guinea). Malar J 2006, 23:21.

[11] Ridl F, Bass C, Torrez M, Govender D, Ramdeen V, Yellot L, Edu A, Schwabe C, Mohloai P, Maharaj R et al: A pre-intervention study of malaria vector abundance in Rio Muni, Equatorial Guinea: their role in malaria transmission and the incidence of insecticide resistance alleles. Malar J 2008, 7:194. 
[12] Awono-Ambene P, Antonio-Nkondjio C, Toto J, Ndo C, Etang J, Fontenille D, Simard F: Epidemological importance of the Anopheles nili group of malaria vectors in equatorial villages of Cameroon, Central Africa. Sci Med Afr 2009, 1:13 - 20.

[13] Carnevale P, Le Goff G, Toto J, Robert V: Anopheles nili as the main vector of human malaria in villages of southern Cameroon. Med Vet Entomol 1992, 6:135 - 138.

[14] Takken W, Knols B: Malaria vector control: current and future strategies. Trends Parasitol 2009, 25:101 - 104 .

[15] Prugnolle F, Durand P, Neel C, Ollomo B, Ayala D, Arnathau C, Etienne L, MpoudiNgole E, Nkoghe D, Leroy E et al: African great apes are natural hosts of multiple related malaria species, including Plasmodium falciparum. Proc Natl Acad Sci U S A 2010, 107:1458 - 1463.

[16] Prugnolle F, Ollomo B, Durand P, Yalcindag E, Arnathau C, Elguero E, Berry A, Pourrut X, Gonzalez J, Nkoghe D et al: Africa monkeys are infected by Plasmodium falciparum nonhuman primate-specific strains. Proc Natl Acad Sci U S A 2011, 108:11948 - 11953.

[17] Duval L, Fourment M, Nerrienet E, Rousset D, Sadeuh S, Goodman S, Andriaholinirina N, Randrianarivelojosia M, Paul R, Robert V et al: African apes as reservoir of Plasmodium falciparum and the origin and diversification of the Laverania subgenus. Proc Natl Acad Sci U S A 2010, 107:10561 - 10566.

[18] Gillies M, De Meillon B: The Anophelinae of Africa South of the Sahara. South Africa Institute of Medical Research Johannesburg, South Africa 1968.

[19] Brunhes J, Le Goff G, Manga L, Geoffroy B: Anopheles afro-tropicaux. IV - Mise au point sur les espèces et sous-espèces du groupe Anopheles (Cellia) moucheti; rehabilitation d'An. (C.) multicinctus et d'An. (Cellia) garnhami basilewskyi. Annales de la Société Entomologique de France 1998, 34:397 - 405.

[20] Gillies M, Coetzee M: A supplement to the Anophelinae of Africa south of the Sahara (Afrotropical region). Pub South Afr Inst Med Res 1987, 55:143.

[21] Antonio-Nkondjio C, Simard F, Cohuet A, Fontenille D: Morphological variability in Anopheles mouchet $i$ is not indicative of speciation: evidences from sympatric south Cameroon populations. Infect Genet Evol 2002, 2:69 - 72.

[22] Fontenille D, Cohuet A, Awono-Ambene H, Antonio-Nkondjio C, Wondji C, Kengne P, Dia I, Boccolini J, Duchemin J, Rajaonarivelo V et al: Systématique et biologie des anophèles vecteurs de Plasmodium en Afrique, données récentes. Med Trop 2003, 63:247 - 253.

[23] Kengne P, Antonio-Nkondjio C, Awono-Ambene H, Simard F, Awolola T, Fontenille D: Molecular differentiation of three closely related members of the mosquito species complex Anopheles moucheti, by mitochondrial and ribosomal DNA polymorphism. Med Vet Entomol 2007, 21:177 - 182. 
[24] Harbach R: Anopheles classification. Mosquito Taxonomic Inventory. http://mosquitotaxonomic-inventoryinfo/ 2012.

[25] Sinka M, Bangs M, Manguin S, Coetzee M, Mbogo C, Hemingway J, Patil A, Temperley W, Gething P, Kabaria $C$ et al: The dominant Anopheles vectors of human malaria in Africa, Europe and the Middle East: occurrence data, distribution maps and bionomic precis. Parasit Vectors 2010, 3:117.

[26] Hay S, Sinka M, Okara R, Kabaria C, Mbithi P, Tago C, Benz D, Gething P, Howes R, Patil A et al: Developing global maps of the dominant Anopheles vectors of human malaria. PLoS Med 2010, 7:e1000209.

[27] Njan Nloga A, Robert V, Toto J, Carnevale P: Anopheles moucheti, vecteur principal du paludisme au sud-Cameroun. Bulletin de Liaison et de Documentation de l'OCEAC 1993, $26: 63-67$.

[28] Antonio-Nkondjio C, Kerah C, Simard F, Awono-Ambene H, Mouhamadou C, Tchuinkam T, Fontenille D: Complexity of malaria vectorial system in Cameroon: contribution of secondary vectors to malaria transmission. J Med Entomol 2006, 43:1215 - 1221.

[29] Awolola T, Okwa O, Hunt R, Ogunrinade A, Coetzee M: Dynamics of malaria vector populations in coastal Lagos, south-western Nigeria. Ann Trop Med Parasitol 2002, $96: 75-82$.

[30] Njan Nloga A, Robert V, Toto J, Carnevale P: Anopheles moucheti, vecteur principal du paludisme au sud-Cameroun. Bull Liais Doc OCEAC 1993, 26:63 - 67.

[31] Elissa N, Karch S, Bureau P, Ollomo B, Lawoko M, Yangari P, Ebang B, Georges A: Malaria transmission in a region of savanna-forest mosaic, Haut-Ogooue, Gabon. J Am Mosq Control Assoc 1999, 15:15 - 23.

[32] Sylla E, Kun J, Kremsner P: Mosquito distribution and entomological inoculation rates in three malaria-endemic areas in Gabon. Trans $R$ Soc Trop Med Hyg 2000, 94:652 $-656$.

[33] Njan Nloga A: Bioécologie et rôle vecteur du paludisme d'Anopheles moucheti à Ebogo au Cameroun. Thèse de doctorat Université de Montpellier II Sciences et Techniques du Languedoc 1994:233p.

[34] Livadas G, Mouchet J, Gariou J, Chastang R: Peut-on envisager l'eradication du paludisme dans la region forestiere du Sud-Cameroun? Revista di Malariologia 1958, 37:229 - 256.

[35] Antonio-Nkondjio C, Ndo C, Kengne P, Mukwaya L, Awono-Ambene H, Fontenille D, Simard F: Population structure of the malaria vector Anopheles moucheti in the equatorial forest region of Africa. Malar J 2008, 7:120. 
[36] Antonio-Nkondjio C, Ndo C, Awono-Ambene H, Ngassam P, Fontenille D, Simard F: Population genetic structure of the malaria vector An. moucheti in south Cameroon forest region. Acta Trop 2007, 101:61 - 68.

[37] Annan Z, Kengne P, Berthomieu A, Antonio-Nkondjio C, Rousset F, Fontenille D, Weill M: Isolation and characterisation of polymorphic microsatellite markers from the mosquito Anopheles moucheti, malaria vector in Africa. Mol Ecol Notes 2003, 3:56 57.

[38] Brunhes J, LeGoff G, Geoffroy B: Afro-tropical anopheline mosquitoes: description of three new species: Anopheles carnevalei sp. nov., An. hervyi sp. nov and An. dualaensis sp. nov., and resurrection of An. rageaui Mattingly and Adam. J Am Mosq Control Assoc 1999, 15:552 - 558 .

[39] Awono-Ambene H, Kengne P, Simard F, Antonio-Nkondjio C, Fontenille D: Description and bionomics of Anopheles (Cellia) ovengensis (Diptera: Culicidae), a new malaria vector species of the Anopheles nili group from south Cameroon. J Med Entomol 2004, 41:561 - 568 .

[40] Okara R, Sinka M, Minakawa N, Mbogo C, Hay S, Snow R: Distribution of the main malaria vectors in Kenya. Malar J 2010, 9:69.

[41] Antonio-Nkondjio C, Meunier J, Awono-Ambene H, Fontenille D: La présence de bovins comme hôte alternatifs peut elle modifier le comportement trophique des vecteurs du paludisme en zone de forêt? Sciences et Médecines d'Afrique 2009, 1:7 - 12.

[42] Le Goff G, Carnevale P, Robert V: Low dispersion of anopheline malaria vectors in the African equatorial forest. Parasite 1997, 2:187 - 189.

[43] Adja A, N'goran K, Kengne P, Koudou G, Toure M, Koffi A, Tia E, Fontenille D, Chandre F: Transmission vectorielle du paludisme en savane arborée à Ganse en Cote d'Ivoire. Med Trop 2006, 66:449 - 455.

[44] Krafsur E: Anopheles nili as a vector of malaria in a lowland region of Ethiopia. Bulletin of the World Health Organization 1970, 42:466 - 471.

[45] Awono-Ambene H, Simard F, Antonio-Nkondjio C, Cohuet A, Kengne P, Fontenille D: Multilocus enzyme electrophoresis supports speciation within the Anopheles nili group of Malaria vectors in Cameroon. Am J Trop Med Hyg 2006, 75:656 - 658.

[46] Kengne P, Awono-Ambene H, Antonio-Nkondjio C, Simard F, Fontenille D: Molecular identification of the Anopheles nili group African malaria vectors. Med Vet Entomol 2003, 17:67 - 74.

[47] Berthomieu A, Kengne P, Awono-Ambene H, Raymond M, Fontenille D, Weill M: Isolation and characterization of microsatellite DNA markers in the malaria vector Anopheles nili. Mol Ecol Notes 2003, 3:392 - 393. 
[48] Ndo C, Antonio-Nkondjio C, Cohuet A, Ayala D, Kengne P, Morlais I, Awono-Ambene P, Couret D, Ngassam P, Fontenille D et al: Population genetic structure of the malaria vector Anopheles nili in sub-Saharan Africa. Malaria Journal 2010, 9(1):161.

[49] Ndo C: Bioécologie et structure génétique des populations d'Anopheles moucheti sl et d'Anopheles nili vecteurs majeurs du paludisme en Afrique subsaharienne. Thèse de Doctorat PhD Faculté des Sciences Université de Yaoundé I Cameroun 2011:286p.

[50] Sharakhova M, Antonio-Nkondjio C, Xia A, Ndo C, Awono-Ambene H, Simard F, Sharakhov I: Cytogenetic map for Anopheles nili: Application for population genetics and comparative physical mapping. Infection, Genetics and Evolution 2010, 11:746 754.

[51] Peery A, Sharakhova M, Antonio-Nkondjio C, Ndo C, Weill M, Simard F, Sharakhov I: Improving the population genetics toolbox for the study of the African malaria vector Anopheles nili: microsatellite mapping to chromosomes. Parasites \& Vectors 2011, 4:202.

[52] Liu W, Li Y, Learn G, Rudicell R, Robertson J, Keele B, Ndjango J, Sanz C, Morgan D, Locatelli $S$ et al: Origin of the human malaria parasite Plasmodium falciparum in gorillas. Nature 2010, 467(7314):420 - 425. 